\title{
TIMELESS PERSPECTIVE VS. DISCRETIONARY MONETARY POLICY IN FORWARD-LOOKING MODELS
}

Bennett T. McCallum

Edward Nelson

Working Paper 7915

http://www.nber.org/papers/w7915

\author{
NATIONAL BUREAU OF ECONOMIC RESEARCH \\ 1050 Massachusetts Avenue \\ Cambridge, MA 02138 \\ September 2000
}

We are grateful to Mark Gertler, Douglas Laxton, Andre Minella, Jon Steinsson, Lars Svensson, and Alex Wolman for helpful discussion and comments. The views expressed in this paper are the authors' and should not be interpreted as those of the National Bureau of Economic Research, the Bank of England or its Monetary Policy Committee.

(C) 2000 by Bennett T. McCallum and Edward Nelson. All rights reserved. Short sections of text, not to exceed two paragraphs, may be quoted without explicit permission provided that full credit, including (C) notice, is given to the source. 
Timeless Perspectives vs. Discretionary Monetary Policy

In Forward-Looking Models

Bennett T. McCallum and Edward Nelson

NBER Working Paper No. 7915

September 2000

JEL No. E52, E58, E30

\title{
ABSTRACT
}

This paper reviews the distinction between the timeless perspective and discretionary modes of monetary policymaking, the former representing rule-based policy as recently formalized by Woodford (1999b). In models with forward-looking expectations, this distinction is greater than in the models that have been typical in the rules-vs.-discretion literature; typically there is a second inefficiency from discretionary policymaking, distinct from the familiar inflationary bias. The paper presents calculations of the quantitative magnitude of this second inefficiency, using calibrated models of two types prominent in the current literature. In addition, it examines the distinction between instrument rules and targeting rules; the results indicate that targeting-rule outcomes can be very closely approximated by instrument rules. Also included is a brief investigation of operationality issues, involving the unobservability of current output and the possibility that an incorrect concept of the natural-rate level of output, essential in measuring the output gap, is used by the policymaker. In all of the cases examined, the unconditional average performance of timeless perspective policymaking is at least as good as that provided by optimal discretionary behavior.

\author{
Bennett T. McCallum \\ Graduate School of Industrial Administration \\ Carnegie Mellon University \\ Pittsburgh, PA 15213 USA \\ Tel. (412) 268-2347 \\ and NBER \\ bm05@andrew.cmu.edu \\ Edward Nelson \\ Bank of England \\ Threadneedle Street \\ London EC2R 8AH U.K. \\ Tel +44 2076015692 \\ ed.nelson@bankofengland.co.uk
}




\section{Introduction}

Recent analysis by Clarida, Gali, and Gertler (1999), Jensen (1999), Svensson and Woodford (2000), and especially Woodford (1999a, 1999b, 2000) has been highly productive in advancing the profession's understanding of optimal monetary policy. Specifically, these papers emphasize the importance for policy purposes of the distinction between macroeconomic models (of private behavior) that are "forward looking"-i.e., that include expectations of future values of endogenous variables - and those that are not. This distinction — applied to the structural form of the model—is of great theoretical significance, since models derived from optimizing analysis almost invariably include expectations of future variables. A major point of the cited literature is that there is, in forward-looking models, an inefficiency that results from discretionary policymaking, relative to that of an optimal policy rule, that obtains in addition to the familiar inflationary bias. (The inflationary bias has been extensively discussed in a huge literature that typically uses non-forward-looking models). This point, which is implicit in earlier work by Currie and Levine (1993), among others, has been valuably emphasized in the cited papers, especially in Woodford (1999b).

There are many associated issues, nevertheless, that remain to be considered. One of these is the quantitative extent to which an optimal policy rule provides improved outcomes relative to (optimal) discretionary behavior. That magnitude depends, of course, on the specification of the model that is utilized - its parameter values and general aspects of the specification - and an exploration is clearly warranted. A related topic, moreover, concerns the distinction proposed by Svensson $(1997,1999)$ between "targeting rules" and "instrument rules." Is there in fact a major difference? Or can 
target-rule outcomes be closely approximated by instrument-rule procedures? Third, in the context of optimal policy-rule analysis, issues concerning operationality—stressed by McCallum and Nelson (1999b) — arise naturally. Is the superiority of rule-based over discretionary policymaking enhanced or diminished by realistic specification of information available to the policymaker? Finally, how important is this newlyrecognized source of discretionary suboptimality in comparison with the more familiar inflationary bias?

Each of the foregoing issues will be explored in what follows. In addition, we begin with an exposition of the basic analysis that emphasizes Woodford's concept of a "timeless perspective" and its intimate connection to previous concepts of rule-based policymaking.

\section{Basic Analysis}

As an illustrative framework, let us begin with the stylized forward-looking macroeconomic model that is utilized by Woodford (1999b, 2000) and also is a special case of the models in Clarida, Gali, and Gertler (CGG) (1999) and Jensen (1999). ${ }^{1}$ This simplest version features only a forward-looking price adjustment or aggregate supply relation of the Calvo-Rotemberg type, augmented with shocks that keep the current natural-rate level of output from being economically efficient. ${ }^{2}$ Denoting inflation in period $t$ by $\pi_{t}$ and the output gap by $y_{t}$, this relation is

\footnotetext{
${ }^{1}$ The latter two papers permit first-order autoregressive processes for the shock variables, which makes their systems somewhat richer than that considered by Woodford, and also consider model variants that include lagged inflation and output-gap terms.

${ }^{2}$ For some discussion of the nature of the $u_{t}$ shock in (1) below, see Woodford (1999b, 2000), CGG (1999, pp. 1566-67), and Erceg, Henderson, and Levin (1999). Our notation differs slightly from that of any of the cited authors.
} 
$\pi_{t}=\alpha y_{t}+\beta \mathrm{E}_{t} \pi_{t+1}+u_{t}$

where $\alpha>0,0<\beta<1$, and $u_{t}$ is the shock term. For simplicity, we initially assume that the process generating $u_{t}$ is white noise. The model that we (and the cited authors) have in mind actually also includes an optimizing IS-type demand relationship of the form $y_{t}=\mathrm{E}_{t} y_{t+1}+b_{1}\left(R_{t}-\mathrm{E}_{t} \pi_{t+1}\right)+v_{t}, \quad b_{1}<0$

where $R_{t}$ is the central bank's interest rate instrument and $v_{t}$ is a preference or government spending shock. ${ }^{3}$ But we shall at first pretend that the central bank (CB) can directly control $\pi_{t}$ as an instrument-an assumption that is very common in the literature and is innocuous in the present context. ${ }^{4}$ In Section 4 we will extend the analysis in a manner that involves inclusion of (2) and use of an interest rate instrument.

The central bank's objective function at time $t$ is taken to be of the form

Minimize $\mathrm{E}_{t} \boldsymbol{\Sigma}_{j=0}^{\infty} \beta^{\mathrm{j}}\left(\pi_{t+j}^{2}+\omega y_{t+j}^{2}\right)$,

which Woodford (1999a) has shown to be consistent with individual optimality in terms of agents' preferences under certain reasonable conditions. Consequently, the CB's problem at some point in time, here taken (without loss of generality) to be $t=1$, can be expressed as minimization of the Lagrangian expression

$$
\begin{aligned}
L_{1} & =\mathrm{E}_{1}\left[\left(\pi_{1}^{2}+\omega y_{1}^{2}\right)+\beta\left(\pi_{2}^{2}+\omega y_{2}^{2}\right)+\ldots\right. \\
& \left.+\lambda_{1}\left(\alpha y_{1}+\beta \pi_{2}+u_{1}-\pi_{1}\right)+\beta \lambda_{2}\left(\alpha y_{2}+\beta \pi_{3}+u_{2}-\pi_{2}\right)+\ldots\right]
\end{aligned}
$$

\footnotetext{
${ }^{3}$ Since we have written (2) in terms of the output gap - a somewhat undesirable practice since the IS relationship fundamentally pertains to aggregate demand, not the output gap - the $v_{t}$ term also includes the expected change in the log of the natural rate of output.

${ }^{4}$ If the relation (2) is included as an additional constraint, with optimization then conducted with respect to $R_{t}$ as well as $y_{t}$ and $\pi_{t}$, the Lagrange multiplier attached to this constraint equals zero for all $t$.
} 
with respect to $\pi_{1}, \pi_{2}, \ldots$, and $y_{1}, y_{2}, \ldots{ }^{5}$ As shown by Woodford (1999b) and CGG (1999), the optimizing conditions include

$\mathrm{E}_{1}\left(2 \omega y_{t}+\alpha \lambda_{t}\right)=0, \quad t=1,2, \ldots$

$\mathrm{E}_{1}\left(2 \pi_{t}+\lambda_{t-1}-\lambda_{t}\right)=0, \quad t=2,3, \ldots$

$2 \pi_{1}-\lambda_{1}=0$.

Here equations (1), (5a), (5b), and (5c) apparently determine optimal values of $\pi_{t}$, $y_{t}$, and $\lambda_{t}$ for period $t=1$ and expected values as of $t=1$ for periods $t=2,3, \ldots$ But these choices entail dynamic inconsistency, since the $\mathrm{CB}$ could re-solve the problem in time period 2 and would then choose $2 \pi_{2}-\lambda_{2}=0$ instead of the condition $2 \pi_{2}+\lambda_{1}-\lambda_{2}=0$ that is suggested by (5b). Thus the standard "commitment" solution, in which the CB implements (5c) and (5a)(5b) with the $\mathrm{E}_{1}$ operators removed, ${ }^{6}$ views the $\mathrm{CB}$ as selecting values in $t=2,3, \ldots$ that it currently considers undesirable from the perspective of its own decision-making process. Since such a pattern of behavior seems highly implausible, this commitment solution does not provide an attractive equilibrium concept.

There is another equilibrium concept, however, involving a different type of commitment, that is much more attractive - as Woodford (1999b) argues convincingly. Instead of using (1), (5a), and (5b) with the start-up condition (5c) to determine paths of $\pi_{t}, y_{t}$, and $\lambda_{t}$ for $t=1,2, \ldots$, the CB can use (1), (5a), and (5b) without any start-up condition by applying (5b) in all periods. This approach, which Woodford terms the "timeless perspective," involves ignoring any conditions prevailing at the regime's inception — say, by imagining that the decision to apply (5a) and (5b) had been made in

\footnotetext{
${ }^{5}$ In (4), the terms $\mathrm{E}_{t} \pi_{t+1}$ from (1) can be written without $\mathrm{E}_{t}$ operators since $\mathrm{E}_{1} \mathrm{E}_{t} \pi_{t+1}=\mathrm{E}_{1} \pi_{t+1}$, by the law of iterated expectations.
} 
the distant past. In this case there is no dynamic inconsistency in terms of the CB's own decision-making process. The values of $\pi_{2}$ and $y_{2}$ chosen by this process in period 2 agree with the values chosen expectationally in period 1.

An alternative description of this mode of policy behavior can be obtained by specifying that our concern is with macroeconomic performance within and across regimes, not with transitions from one regime to another. In this case the analysis supposes that the policy regime being analysed has been in effect long enough that initial conditions, which obtained at the time of its inception, have become irrelevant. This is the conception adopted by Lucas (1980, p. 205), Lucas and Sargent (1981, p. xxxvii), Taylor (1979), and others. Our contention is that this is the most appropriate presumption for monetary policy analysis. To us it seems implausible that private agents could immediately begin forming expectations consistent with any new policy regime, following a regime change, as is assumed by some alternative approaches. The basic rational expectations approach requires that a policy regime has been in effect long enough for private agents to understand it and believe in its continuation.

It is perhaps worth mentioning that this timeless-perspective optimality concept agrees precisely with what has been viewed by most analysts, since publication of the Barro and Gordon (1983) exposition of the Kydland and Prescott (1977) insights, as "policymaking according to a rule." The various quotes in Woodford (1999b) taken from McCallum (1999a) illustrate that agreement, ${ }^{7}$ as does Woodford's placement of his analysis in a section of his (1999b) paper entitled "Rule-Based Policymaking." The modification that King and Wolman (1999, pp. 374-375) make to the commitment case in

\footnotetext{
${ }^{6}$ When period $t+j$ comes around, the CB can by assumption observe $y_{t+j}$ and $\pi_{t+j}$, so it can implement (5a)(5b) exactly.
} 
their study of optimal monetary policy, also corresponds to adopting a timelessperspective. ${ }^{8}$ It is also worth emphasizing that many studies of optimal monetary policy in forward-looking models have considered policies which are labelled "commitment," but which (since these policies ignore the period 1 first order condition and use only the remaining portion of the commitment conditions) should really be regarded as the timeless perspective policy. Recent examples in this last category of studies including CGG (1999), Batini and Nelson (2000), and Smets (2000).

Before continuing, it will be useful to derive the counterpart of conditions (5) provided by "discretionary" policymaking, i.e., a process that presumes period-by-period reoptimization involving each period's start-up conditions. In this case the derivatives with respect to the terms in the Lagrangian expression (4) that correspond to $E_{t} \pi_{t+1}$ in (1) are all equal to zero. ${ }^{9}$ Thus the counterpart of $(5 b)$ becomes

$\mathrm{E}_{1}\left(2 \pi_{t}-\lambda_{t}\right)=0 \quad t=1,2, \ldots$

which is similar to the first-period condition (5c) in the commitment optimization but now applies to each period. Note that discretion can be characterised by the absence of the lagged Lagrange multiplier in the CB's first order condition, as stressed by Woodford (1999a).

In addition, let us express the policy-optimality conditions with the Lagrange mutipliers $\lambda_{t}$ substituted out. Then for the discretionary optimum we obtain from (6) and (5a) the following:

\footnotetext{
${ }^{7}$ See, for example, Woodford's (1999b) footnote 22.

${ }^{8}$ King and Wolman's modification is patterned after an analogous procedure in Kydland and Prescott's (1980) study of optimal tax policy.

${ }^{9}$ The reason is somewhat more complex than in the Barro-Gordon (1983) model, which is not forward looking: see Woodford (1999b, pp. 308-9) or CGG (1999, p. 1672).
} 
$\pi_{t}=-(\omega / \alpha) y_{t}$

By contrast, the timeless-perspective, rule-based optimality condition implied by ( $5 \mathrm{~b})$ and $(5 a)$ is

$\pi_{t}=-(\omega / \alpha)\left(y_{t}-y_{t-1}\right)$.

The latter expression is equivalent to (8) or (7) in Woodford (1999b) and to (4.18) of CGG (1999). It is of some interest to note that in the special case $\omega=\alpha$, the TP rule (8) calls for nominal income growth targeting. This point is related to the findings reported by Jensen (1999).

To determine how inflation and the output gap behave in the timeless perspective equilibrium we obtain the rational expectations $(\mathrm{RE})$ solution to the model consisting of the policy rule (8) and the private behavioral relation (1). In particular, we look for the minimal state variable (MSV) solution that excludes bubbles and sunspots, as discussed by McCallum (1999b). Thus we conjecture that $\pi_{t}$ and $y_{t}$ are related to the clearlyrelevant state variables $y_{t-1}$ and $u_{t}$ as follows:

$\pi_{t}=\phi_{11} y_{t-1}+\phi_{12} u_{t}$

$y_{t}=\phi_{21} y_{t-1}+\phi_{22} u_{t}$

Then $\mathrm{E}_{t} \pi_{t+1}=\phi_{11}\left(\phi_{21} y_{t-1}+\phi_{22} u_{t}\right)$ and substitution into (1) and (8) yields the undetermined-coefficient relationships:

$\phi_{11}=\alpha \phi_{21}+\beta \phi_{11} \phi_{21}$

$\phi_{12}=\alpha \phi_{22}+\beta \phi_{11} \phi_{22}+1$

$\phi_{11}=(\omega / \alpha)\left(1-\phi_{21}\right)$

$\phi_{21}=-(\omega / \alpha) \phi_{22}$

From (10a) and (10c) we find that $\phi_{21}$ satisfies 
$\beta \phi_{21}{ }^{2}-\gamma \phi_{21}+1=0$

where $\gamma=\left(1+\beta+\alpha^{2} / \omega\right)$. The relevant root, according to both the stability and MSV criteria, is

$\phi_{21}=\left[\gamma-\left(\gamma^{2}-4 \beta\right)^{0.5}\right] / 2 \beta$,

which satisfies $0<\phi_{21}<1$. Following CGG (1999), let us use the symbol $\delta=\phi_{21}$. Then the values for $\phi_{11}, \phi_{12}$, and $\phi_{22}$ can be found to be $\phi_{11}=(\omega / \alpha)(1-\delta), \phi_{12}=1 /(\gamma-\beta \delta), \phi_{22}$ $=-(\alpha / \omega) /(\gamma-\beta \delta)$ and the solutions are

$\pi_{t}=(\omega / \alpha)(1-\delta) y_{t-1}+(\gamma-\beta \delta)^{-1} u_{t}$

and

$y_{t}=\delta y_{t-1}-[(\alpha / \omega) /(\gamma-\beta \delta)] u_{t}$.

These can be shown, with some tedious algebra, to agree with solution expressions reported by CGG (1999, e.g. (8.1)).

Finally, to find the MSV equilibrium under discretionary optimal policy, we use (7) rather than (8) as the policy rule. In a system consisting of (1) and (7), there are no clearly-relevant state variables other than $u_{t}$, so we conjecture a solution of the form $\pi_{t}=\phi_{1} u_{t}$

$y_{t}=\phi_{2} u_{t}$.

Then $\mathrm{E}_{t} \pi_{t+1}=0$ and the values of $\phi_{1}$ and $\phi_{2}$ are found to be $\omega /\left(\omega+\alpha^{2}\right)$ and $-\alpha /\left(\omega+\alpha^{2}\right)$.

Neither Woodford (1999b) nor CGG (1999) includes an analysis of the relative losses - the unconditional expectations of the objective function - under the two modes of policy-making. Indeed, they do not actually put forth any claim that the timelessperspective losses are generally smaller than those from discretionary policymaking. We do not here attempt a general algebraic analysis, but we wish to examine the issue 
quantitatively by use of models calibrated with specific parameter values. Such an analysis will be included in the next section.

\section{Quantitative Analysis}

Our agenda now is to specify values for the model's parameters $\alpha, \beta$, and $\omega$, find the RE solutions described above, and report for a chosen value of the variance of $u_{t}$ and chosen autocorrelation properties, if desired - the average values of the loss function. The average values of the intertemporal loss function (3) are proportional to the mean of the instantaneous loss function, which is what we report. ${ }^{10}$ In what follows, these values are calculated using asymptotic formulae for the moments of the variables in the model (e.g., Hamilton [1994, p. 265]). ${ }^{11}$ We use our modification of the QZ algorithm of Klein (2000) to obtain the MSV solution.

Table 1 reports values of the loss function for a range of $\alpha$ and $\omega$ values, with $\beta$ kept at 0.99 throughout. For $\alpha$, we would suggest that actual values probably lie between 0.01 and 0.05; see, e.g., the estimates in Gali and Gertler (1999). For the central-bank preference parameter $\omega$ our range of 0.01 to 1.0 includes values that place almost all weight on inflation variability and ones that give much weight to output variability. Since we are using quarter-year time periods, equal weights in terms of annualized inflation (as in the original Taylor rule) imply $\omega=0.25$. The standard deviation of the white-noise $u_{t}$ shocks is taken to be 0.005 , our variables being measured

\footnotetext{
${ }^{10}$ Here we follow the example of King and Wolman (1999), Rotemberg and Woodford (1999), and Rudebusch and Svensson (1999) in our use of the unconditional expectation of (3) as the policy criterion.
} 


\section{Table 1}

\section{Losses with TP and DIS Policy Behavior, Basic C-R Model}

(Reported values are losses times $\left.10^{5}, \mathrm{TP} / \mathrm{DIS}\right)$

\begin{tabular}{|c|c|c|c|c|}
\hline & \multicolumn{4}{|c|}{ Value of $\omega$} \\
\hline Value of $\alpha$ & 0.01 & 0.10 & 0.25 & 1.0 \\
\hline 0.10 & $0.96 / 1.25$ & $1.84 / 2.27$ & $2.07 / 2.40$ & $2.28 / 2.48$ \\
\hline 0.05 & $1.54 / 2.00$ & $2.15 / 2.44$ & $2.28 / 2.48$ & $2.40 / 2.49$ \\
\hline 0.01 & $2.28 / 2.48$ & $2.45 / 2.50$ & $2.50 / 2.50$ & $2.50 / 2.50$ \\
\hline
\end{tabular}

Table 2

Losses with TP and DIS Policy Behavior, C-R Model with $\rho_{u}=0.8$

(Reported values are losses times $\left.10^{5}, \mathrm{TP} / \mathrm{DIS}\right)$

\begin{tabular}{|c|c|c|c|c|}
\hline \multirow{2}{*}{} & \multicolumn{4}{|c|}{ Value of $\omega$} \\
\hline Value of $\alpha$ & 0.01 & 0.10 & 0.25 & 1.0 \\
\hline 0.10 & $5.51 / 9.52$ & $29.4 / 80.5$ & $48.1 / 117.4$ & $83.0 / 147.6$ \\
\hline 0.05 & $16.21 / 41.3$ & $59.4 / 131.1$ & $83.0 / 147.6$ & $116.4 / 157.2$ \\
\hline 0.01 & $83.0 / 147.6$ & $133.8 / 159.1$ & $146.8 / 160.0$ & $158.9 / 160.4$ \\
\hline
\end{tabular}

\footnotetext{
${ }^{11}$ These values have been checked by comparison with averages of the same statistics across 100 stochastic simulations (200 periods).
} 
in fractional (rather than percentage) units. ${ }^{12}$ Thus the annualized standard deviation is about 2.0 percent, slightly less than is realistic for the U.S. economy. In each entry of Table 1 there are two numbers; the first is the average (i.e., unconditional expectation) loss for the timeless-perspective (TP) solution and the second is for the discretionary (DIS) solution. From the table it can be seen that the TP policy produces smaller losses than the DIS policy for all examined values of $\alpha$ and $\omega$. The quantitative extent of the difference is, however, rather small.

To consider whether this small difference represents a robust finding, let us modify the model somewhat. In particular, we now assume that the $u_{t}$ shock process is serially correlated according to a first-order autoregressive specification with an autoregression parameter value of 0.8 . This change will result in solution processes for inflation and the output gap that feature considerable persistence, much more like actual data than those generated by the basic model with white noise $u_{t}$ shocks. We retain a value of 0.005 for the standard deviation of the innovation driving the $u_{t}$ process, so the value of the variance of $u_{t}$ itself is larger than before by a factor of $\left[1 /\left(1-0.8^{2}\right)\right]=2.78$. For that reason alone the values of the losses will be greater than before, but not to the extent found. These magnitudes are of some interest on their own, but it is the relative values for the TP and DIS policies that are of primary interest.

Results are shown in Table 2. There it will be seen that there is a somewhat greater difference than before in the TP and DIS outcomes. The ratios of DIS to TP losses, that is, are somewhat larger than in the case with white noise shocks. This is not too surprising, for the fundamental advantage of the TP rule is that it takes correct

\footnotetext{
12 The value chosen for this standard deviation directly influences the values of calculated losses, but does
} 
account of private sector expectations, and therefore of intertemporal aspects of the situation, which are more pronounced when serial correlation of the shocks is included.

An alternative specification that tends to generate persistence in inflation, and has been prominent in recent research, is provided by replacement of price-adjustment relation (1) with the following:

$\pi_{t}=\alpha y_{t}+\beta \theta \mathrm{E}_{t} \pi_{t+1}+\beta(1-\theta) \pi_{t-1}+u_{t} . \quad 0<\theta<1$

Relations of this general type have been promoted by Fuhrer (1997) and Fuhrer and Moore (1995), among others, and are considered by CGG (1999) and Jensen (1999). To find the TP policy rule with (17) replacing (1), we proceed as in Section 2 and obtain the following first-order conditions in place of (5):

$\mathrm{E}_{1}\left(2 \omega y_{t}+\alpha \lambda_{t}\right)=0 \quad t=1,2, \ldots$

$\mathrm{E}_{1}\left[2 \pi_{t}+\theta \lambda_{t-1}-\lambda_{t}+\beta^{2}(1-\theta) \lambda_{t+1}\right]=0 \quad t=2,3, \ldots$

$2 \pi_{1}-\lambda_{1}+\beta^{2}(1-\theta) \lambda_{2}=0$.

Adopting the timeless perspective, then, and substituting out the $\lambda_{t}$ multipliers between (18a) and (18b), yields the optimality condition

$\pi_{t}=(\omega / \alpha)\left[\theta y_{t-1}-y_{t}+\beta^{2}(1-\theta) \mathrm{E}_{t} y_{t+1}\right] \quad t=1,2, \ldots$

Here $\mathrm{E}_{t} y_{t+1}$ appears instead of $y_{t+1}$ since the latter is not known at $t$.

For the case of discretionary optimization, interestingly, there are two possible concepts. First, one might conceive of the CB as implementing (18a) and (18c) in period 1 and planning to implement (18a) and (18b) in each subsequent period. When period 2 arrives, however, the CB re-solves its problem and again implements (18a) and (18c), now updated to period 2. Indeed, in this case the $\mathrm{CB}$ re-solves and implements this 
solution in each period. With the Lagrange multipliers substituted out, the relevant optimality condition is

$\pi_{t}=-(\omega / \alpha)\left[y_{t}-\beta^{2}(1-\theta) \mathrm{E}_{t} y_{t+1}\right]$,

where again it is recognized that $y_{t+1}$ is not known in period $t$. The second concept, used by CGG (1999, p. 1692) and Jensen (1999), does not involve the dynamic inconsistency implied by the first. Instead of planning to implement (18b) in future periods, the CB recognizes in period 1 that in period 2 it will behave just as it does in period 1 . In minimizing (3), accordingly, $E_{1} \pi_{2}$ in the constraint (17) for period 1 will be replaced with $\rho_{1} \pi_{1}$, where $\rho_{1}$ is a parameter of the equilibrium solution expression $\pi_{t}=$ $\rho_{1} \pi_{t-1}+\rho_{2} u_{t}$. In the present case with white noise $u_{t}$, accordingly, the relevant optimality condition with this conception of discretionary behavior is $\pi_{t}=-(\omega / \alpha)\left[\left(1-\beta \theta \rho_{1}\right) y_{t}-\beta^{2}(1-\theta) \mathrm{E}_{t} y_{t+1}\right]$

Thus there is a smaller responsiveness of inflation (and larger responsiveness of output) to shocks than would be present if policy behavior were as implied by (20). Since (21) seems to reflect a more standard version of discretion than (20), it will be used in what follows. $^{13}$

Results are reported in Table 3 for the case in which (17) describes price adjustment behavior, with $\theta=0.5$, when $u_{t}$ is white noise. As in Table 2, the ratio of DIS losses to TP losses is somewhat larger than in Table 1, where there is little serial correlation of the model's variables, but not by a great amount. In all cases covered by our $\alpha$ and $\omega$ values, the TP losses are smaller than the DIS losses.

\footnotetext{
${ }^{13}$ We proceed computationally by assuming a value for $\rho_{1}$, solving the model conditional on that value, determining the value implied by the solution, and iterating. For an alternative, dynamic programming approach to the problem, see Steinsson (2000).
} 


\section{Table 3}

\section{Losses with TP and DIS Behavior, Model Including (17)}

(Reported values are losses times $10^{5}, \mathrm{TP} / \mathrm{DIS}$ )

\begin{tabular}{|c|c|c|c|c|}
\hline \multirow{2}{*}{} & \multicolumn{4}{|c|}{ Value of $\omega$} \\
\hline Value of $\alpha$ & 0.01 & 0.1 & 0.25 & 1.0 \\
\hline 0.10 & $1.36 / 1.48$ & $4.56 / 5.45$ & $6.60 / 8.17$ & $10.6 / 13.7$ \\
\hline 0.05 & $2.99 / 3.44$ & $7.83 / 9.83$ & $10.6 / 13.7$ & $15.8 / 20.4$ \\
\hline 0.01 & $10.6 / 13.7$ & $19.7 / 24.5$ & $23.4 / 27.7$ & $27.9 / 30.0$ \\
\hline
\end{tabular}

Table 4

\section{Losses with Interest Instrument Versions of TP and DIS}

Behavior, Basic Model with $\alpha=0.05$ and $\mu_{2}=0$

(Reported values are losses times $\left.10^{5}, \mathrm{TP} / \mathrm{DIS}\right)$

\begin{tabular}{|c|c|c|c|c|}
\hline Value of & \multicolumn{4}{|c|}{ Value of $\omega$} \\
\hline$\mu_{1}$ & 0.01 & 0.10 & 0.25 & 1.0 \\
\hline 0.5 & $2.90 / 2.86$ & $7.36 / 4.69$ & $23.0 / 5.23$ & $41.4 / 4.29$ \\
\hline 5.0 & $2.45 / 2.43$ & $3.40 / 2.62$ & $3.24 / 2.57$ & $2.94 / 2.52$ \\
\hline 50.0 & $1.58 / 2.03$ & $2.17 / 2.44$ & $2.29 / 2.48$ & $2.41 / 2.49$ \\
\hline 500.0 & $1.54 / 2.00$ & $2.16 / 2.44$ & $2.28 / 2.48$ & $2.40 / 2.49$ \\
\hline
\end{tabular}




\section{Target Rules and Instrument Rules}

Implementation of the optimality conditions of the previous section would correspond to adoption of what Svensson $(1997,1999)$ terms "target rules," as distinct from "instrument rules." In these papers, as well as others, Svensson has argued that consideration of target rules is preferable for actual central banks and accordingly for analysts. McCallum (1999a) and McCallum and Nelson (1999b) have, by contrast, suggested that instrument rules are more interesting from a normative point of view. It could also be argued that they are more relevant empirically, i.e., that the actual inflation targeting regimes currently in place in New Zealand, Canada, the United Kingdom, and elsewhere are more satisfactorily represented by formal analytical models with instrument rules than with target rules. ${ }^{14}$ An important part of this argument is that no actual CB has revealed what its loss function is-e.g., what its value of $\omega$ is in expression (3). Of course an argument of this nature can never be conclusive, but we would point out that Woodford (1999b, pp. 287-299) has presented a sophisticated discussion that is predominantly supportive of our position.

A strictly analytical claim made by McCallum (1999a, p. 1493, fn. 17) is that an instrument rule can typically be written so as to imply instrument responses that would tend to bring about the satisfaction of any (feasible) specified target rule. In the context of the present analysis, for example, one could include the optimizing IS relation (2) as part of the model and then specify an instrument rule for $R_{t}$ that is designed to implement an optimality condition such as (8). In this case the rule could be written as

\footnotetext{
${ }^{14}$ See, for example, the discussions of the respective central bank practices given by Archer (2000), Freedman (2000), and King (1999).
} 
$R_{t}=\left(1-\mu_{2}\right)\left\{\bar{r}+\pi_{t}+\mu_{1}\left[\pi_{t}+(\omega / \alpha)\left(y_{t}-y_{t-1}\right)\right]\right\}+\mu_{2} R_{t-1}$

which with $\mu_{1}>0, \mu_{2} \geq 0$ is similar to an extended ${ }^{15}$ version of the Taylor (1993) rule, but with $\pi_{t}+(\omega / \alpha)\left(y_{t}-y_{t-1}\right)$ rather than $\pi_{t}+y_{t}$ as the target variable, i.e., the variable that the rule seeks to keep close to some desired value. If the economy is one in which current aggregate demand can be influenced by $R_{t}$, then as $\mu_{1}$ is increased, the variability of the term in square brackets in (21) should be decreased, yielding an approximation to satisfaction of the optimality condition (8).

To determine whether it is in fact the case that increasing $\mu_{1}$ values would lead to approximate satisfaction of (8) — and likewise of the discretionary optimality condition (7) - consider the figures reported in Table 4. There $\alpha=0.05$ and $\mu_{2}=0$ are retained throughout, with various values of $\omega$ specified and $\mu_{1}$ increased from the Taylor value 0.5 to extremely large magnitudes. ${ }^{16}$ The shock term in relation (2) includes two components, a white noise taste component with standard deviation 0.02 and also $\overline{\mathrm{y}}_{t}-\mathrm{E}_{t} \overline{\mathrm{y}}_{t+1}$, where the natural-rate value $\overline{\mathrm{y}}_{t}$ comes from an $\mathrm{AR}(1)$ process with $\mathrm{AR}$ parameter 0.95 and innovation standard deviation of $0.007 .{ }^{17}$ The results indicate that, at least for this example, ${ }^{18}$ the instrument rule approximates very closely the target-rule optimality conditions for large $\mu_{1}$ values, i.e., strong feedback responses. With $\mu_{1} \geq 50$, for example, the $\omega=1$ case gives TP and DIS loss values of 2.40 and 2.49 , essentially

\footnotetext{
${ }^{15}$ I.e., a version with an $R_{t-1}$ term included to reflect interest rate smoothing.

${ }^{16}$ We are using relation (1) with a white noise shock term.

${ }^{17}$ This component must be included because the IS equation (2) is written in terms of the output gap.

${ }^{18}$ Similar results have also been obtained for the case in which the shock term in (1) is AR(1) with parameter 0.8 .
} 
identical to the target-rule losses shown in Table 1. Thus instrument rules can be written to include target rules as extreme special cases, but are more general.

\section{Operationality}

Exercises such as those of the preceding sections are interesting and even enlightening, but are far removed from the monetary policy problems facing actual central bankers. In reality, CB decision makers have only vague notions about the "true model"-i.e., the workings of the actual economy — and have highly incomplete and imperfect information regarding current values of many variables of macroeconomic importance. Recognition of these features of reality should characterize serious studies of desirable policy. Here we would like to determine how such operationality considerations are related to the issues regarding optimality in forward-looking models that have been considered to this point. Clearly, a complete study is beyond the scope of this paper but some leading problems can be considered. We begin in this section by considering two particular points, ones that have been stressed in previous work by ourselves (McCallum and Nelson (1999b) and McCallum (1999a)).

The first point of concern is the absence of knowledge by the $\mathrm{CB}$ of the current value of real output during a period at the time at which it is setting its interest rate instrument for that period. To be more realistic one could include the most recent period's value $y_{t-1}$, but a preferable approach would be to use $\mathrm{E}_{t-1} y_{t}$. Accordingly, we now investigate the effects of including $\mathrm{E}_{t-1} y_{t}$ in place of $y_{t}$ in instrument rule simulations such as those of Section 4. In addition, we consider cases in which current inflation is 
not observed, so that $\mathrm{E}_{t-1} \pi_{t}$ is used by the $\mathrm{CB}$ in place of $\pi_{t}$, and in which neither of these variables is observed. ${ }^{19}$

A first set of results is shown in Table 5. There the first row repeats results from Table 4 for comparability. Then the second row gives the results with the expected current output gap included in place of the (unobserved) current value. It will be seen that the magnitude of the losses is in this case much greater than with full information, with the extent of the increase positively related to $\omega$ (i.e., to the strength of the response to the imperfectly observed gap variable). For each $\omega$ value considered, it remains true that the TP losses are smaller than the DIS losses. Then in the third row, we suppose that inflation (instead of output) is currently unobservable. In this case, the losses are essentially identical for all $\omega$ values and for both TP and DIS policies. The value of the loss function, moreover, is almost exactly equal to the value of the variance of the $u_{t}$ shock term.

In the fourth row we suppose that both inflation and output are currently unobservable. In this case, the TP losses jump up drastically while the DIS losses increase but by much less. It is understandable that losses could be very large in this case, for the setup is one in which policy is in effect trying to stabilize current variables although they are not observable. In the discretionary case, the separation principle (see Svensson and Woodford, 1999) implies that the attempt is being carried out as efficiently as possible when the $t-1$ expectations are used in the rule in place of current

\footnotetext{
${ }^{19}$ Some analysts might argue that either both, or neither, of the variables $\pi_{t}$ and $y_{t}$ would be observable. Although we have sympathy with the logic, we prefer here to use assumptions that seem more realistic.
} 
Table 5

TP and DIS Losses with Unobservable Output

Basic Model with $\alpha=0.05, \mu_{1}=50$, and $\mu_{2}=0$

(Reported values are losses times $10^{5}, \mathrm{TP} / \mathrm{DIS}$ )

\begin{tabular}{|c|c|c|c|c|}
\hline \multicolumn{5}{|c|}{ Value of $\omega$} \\
\hline $\begin{array}{c}\text { With } y_{t} \text { and } \pi_{t} \\
\text { in Rule }\end{array}$ & $1.58 / 2.03$ & $2.17 / 2.44$ & $2.29 / 2.48$ & $2.41 / 2.49$ \\
\hline $\begin{array}{c}\text { With } \mathrm{E}_{t-1} y_{t} \text { and } \\
\pi_{t} \text { in Rule }\end{array}$ & $3.20 / 3.25$ & $16.1 / 26.7$ & $28.0 / 65.7$ & $64.5 / 260.7$ \\
\hline $\begin{array}{c}\text { With } y_{t} \text { and } \\
\mathrm{E}_{t-1} \pi_{t} \text { in Rule }\end{array}$ & $2.58 / 2.52$ & $2.52 / 2.50$ & $2.51 / 2.50$ & $2.51 / 2.50$ \\
\hline $\begin{array}{c}\text { With } \mathrm{E}_{t-1} y_{t} \text { and } \\
\mathrm{E}_{t-1} \pi_{t} \text { in Rule }\end{array}$ & $12.4 / 3.00$ & $31079 / 6.60$ & $1423.9 / 12.6$ & $8907 / 42.6$ \\
\hline $\begin{array}{c}\text { With } \mathrm{E}_{t-1} y_{t+1}, \\
\mathrm{E}_{t-1} y_{t} \text {, and }\end{array}$ & $3.00 / 3.00$ & $6.60 / 6.60$ & $12.6 / 12.6$ & $42.6 / 42.6$ \\
$\mathrm{E}_{t-1} \pi_{t+1}$ in Rule & & & & \\
\hline
\end{tabular}


observations, but this principle does not apply to the TP case. In that case, it turns out, interestingly, that inclusion of $\mathrm{E}_{t-1} \pi_{t+1}, \mathrm{E}_{t-1} y_{t+1}$, and $\mathrm{E}_{t-1} y_{t}$ yields much better results. In fact the results, shown in the fifth row of Table 5, are essentially equivalent to those given in the fourth row DIS cases. A second set of results, pertaining to the case in which the price adjustment relation (17) replaces (1), is given in Table 6. Qualitatively, the results are much like those of Table 5 . In particular, when neither $\pi_{t}$ nor $y_{t}$ is currently observable, the TP performance is poor-but it can be improved by shifting forward the dates of each variable (whose values are those expected on the basis of $t-1$ data.) In fact, in this case the TP results are superior to those based on the DIS procedure, instead of being equal as in the last row of Table 5.

Our second point of concern is arguably of even greater practical importance. It involves the unobservability of the natural-rate level of output that goes into the CB's measure of the output gap. In this case the nature of the problem is quite different, we contend. Rather than reflecting merely a lack of current information, the problem in this case is largely conceptual — that is, it stems from the existence of various different concepts of the relevant reference value (which we have been calling "natural-rate"). That there are several distinct concepts in use is implicit in the terms used by different researchers and practitioners. In addition to the term "potential," which is frequently used by practitioners, others involve the words "trend," "capacity," "NAIRU," "marketclearing," and "flexible-price," besides "natural-rate." There are perhaps fewer distinct concepts than terms, but there seem to be at least three fundamentally different ones: trend, NAIRU, and flexible-price concepts. And of course there are many ways of 


\section{Table 6}

TP and DIS Losses with Unobservable Output

Model Including (17) with $\alpha=0.05, \mu_{1}=50$, and $\mu_{2}=0$

(Reported values are losses times $\left.10^{5}, \mathrm{TP} / \mathrm{DIS}\right)$

\begin{tabular}{|c|c|c|c|c|}
\hline & \multicolumn{4}{|c|}{ Value of $\omega$} \\
\hline & 0.01 & 0.10 & 0.25 & 1.0 \\
\hline $\begin{array}{l}\text { With } \mathrm{E}_{t} y_{t+1}, y_{t}, \\
\text { and } \pi_{t} \text { in Rule }\end{array}$ & $3.05 / 3.59$ & $7.84 / 9.88$ & $10.6 / 13.7$ & $15.8 / 20.4$ \\
\hline $\begin{array}{c}\text { With } \mathrm{E}_{\mathrm{t}-1} y_{t+1} \text {, } \\
\mathrm{E}_{t-1} y_{t}, \text { and } \pi_{t} \text { in } \\
\text { Rule }\end{array}$ & $4.55 / 4.95$ & $44.5 / 56.7$ & $105.4 / 155.5$ & $368.3 / 693.5$ \\
\hline $\begin{array}{c}\text { With } \mathrm{E}_{t} y_{t+1}, y_{t} \text {, and } \\
\mathrm{E}_{t-1} \pi_{t} \text { in Rule }\end{array}$ & $3.92 / 4.40$ & $8.20 / 10.1$ & $10.9 / 13.8$ & $15.9 / 20.5$ \\
\hline $\begin{array}{c}\text { With } \mathrm{E}_{t-1} y_{t+1}, \\
\mathrm{E}_{t-1} y_{t}, \text { and } \mathrm{E}_{t-1} \pi_{t} \text { in } \\
\text { Rule }\end{array}$ & $4.39 / 3.79$ & $51.2 / 37.6$ & 264.9/117.1 & $6021.5 / 590.4$ \\
\hline $\begin{array}{c}\text { With } \mathrm{E}_{t-1} y_{t+2}, \\
\mathrm{E}_{t-1} y_{t+1} \text {, and } \\
\mathrm{E}_{t-1} \pi_{t+1} \text { in Rule }\end{array}$ & $3.39 / 4.36$ & $11.0 / 26.4$ & $19.6 / 62.6$ & $56.0 / 243.8$ \\
\hline
\end{tabular}


measuring trend output that are quite different in their effects. Furthermore, since reliance on any particular concept will be maintained over time, differences will not possess the orthogonality properties of pure "noise."

Which of the concepts is most appropriate theoretically? From the perspective of dynamic, optimizing analysis, the answer is the third of the three just listed, the flexibleprice concept - i.e., the output level that would prevail in the absence of nominal price stickiness. There have been very few attempts to implement this type of concept empirically, but there is one in McCallum and Nelson (1999b), which we briefly review.

It begins with the assumption that output is produced according to a CobbDouglas production function relating the log of output linearly to the logs of labor and capital $\left(n_{t}\right.$ and $\left.k_{t}\right)$, a deterministic trend, and a shock term $a_{t}$ reflecting the stochastic component of technological change. Then, since $k_{t}$ and $a_{t}$ are given in $t$ whether or not prices are flexible, the difference between the logs of actual and flexible-price output (i.e., the output gap) will be proportional to the difference between actual and flexibleprice labor input, $n_{t}-\overline{\mathrm{n}}_{t}$. For simplicity we assumed that the flexible-price level $\overline{\mathrm{n}}_{t}$ (per period, per person) is a constant. Numerically, we measured $n_{t}$ for the United States, 1955.1-1996.4, as total manhours employed in non-agricultural private industry divided by the civilian labor force. We scaled the measure so that the average value of $n_{t}-\overline{\mathrm{n}}_{t}$ would equal zero. The necessity of this step is undesirable, but on the positive side there was no need to remove any deterministic trend from our $n_{t}-\overline{\mathrm{n}}_{t}$ series. Then using 0.7 as the elasticity of output with respect to labor, we constructed a series for the output gap $y_{t}$, which is shown on p. 28 of our (1999b) and is contrasted with a measure based on simple 
log-linear detrending. This series, with the corresponding output series, gives us a series for $\bar{y}_{t}{ }^{20}$ It has approximately the time series properties assumed above.

An important point is that non-zero realizations of the technology shock $a_{t}$ affect our measure of $\bar{y}_{t}$ one-for-one whereas many detrending procedures, used extensively by academics and to some extent by central banks, remove $a_{t}$ almost entirely from each period's measure of $\bar{y}_{t}$. The same is true, furthermore, for many NAIRU-based procedures. So the question at hand is whether this conceptual discrepancy is of quantitative importance - whether the use of a mistaken concept would induce a large extent of suboptimality into policy rules that rely upon measures of the output gap. We approach this question by assuming that our measure of the gap is correct but the $\mathrm{CB}$ incorrectly uses the measure based on linear detrending in the context of instrument rule (22). We pretend that the $\mathrm{CB}$ has accurate knowledge of the true trend, which is excessively optimistic, so the conceptual error as implemented is only that the CB neglects the influence of $a_{t}$ on $\overline{\mathrm{y}}_{t}$.

Results are reported in Table 7. The loss values reported there can be compared with those in Table 4, in which the experiment is the same except for the postulated mismeasurement of $\bar{y}_{t}$. It is clear that the consequences of the conceptual error are quite substantial, and are much larger for large values of $\omega$. Since these values imply giving more weight to the output gap, the results are consistent with the suggestion of McCallum (1999a) and Orphanides (1999) that it is dangerous to respond strongly to measures of the output gap. Furthermore, Table 7 indicates that the TP outcomes are considerably more

\footnotetext{
${ }^{20}$ Gali and Gertler (1999) also use labor market data, in a different but related manner, in the context of implementing the Calvo specification (equation (1) above).
} 
desirable than those resulting from DIS behavior. This result is in keeping with the spirit of the suggestions of McCallum, Orphanides, and Jensen (1999) that responding to nominal income growth may be more attractive than responding to the level of the output gap.

\section{Inflationary Bias}

An issue of obvious interest is how the magnitudes of the losses shown above in Tables 1-6 compare with those implied by the discretionary inflationary bias that is discussed in the enormous literature that uses non-forward-looking models. The inflationary bias carries over to the forward-looking models, as Woodford (1999b) and CGG (1999) have pointed out, if the CB's objective function includes terms such as $\pi_{t}^{2}+$ $\omega\left(y_{t}-k\right)^{2}$, with $k>0$, reflecting a desire by the CB to keep output above the natural-rate value that would obtain on average in the absence of nominal frictions (i.e., with fully flexible prices). In the model at hand, the magnitude of the bias is simply $(\omega / \alpha) k$, as can be easily verified. To get a clear idea of the magnitudes involved, let us then suppose that $k=0.01$, i.e., that the $\mathrm{CB}$ aims for a level of output that exceeds the natural-rate (i.e., flexible-price) value by one percent. Then if $\omega / \alpha=1$, the bias would be 0.01 and its square, 0.0001 , would be appropriate for comparison with the values in Tables 1, 4, and

5. ${ }^{21}$ Those tables' entries are losses multiplied by $10^{5}$, of course, so in this case the loss value comparable to the first-row, second-column entries of Table 1 would be 10 . More generally, we have the values reported in Table 8 . There it will be seen that for values of $\omega$ greater than 0.1 the inflationary bias is more important, if relevant, than the newlyemphasized dynamic loss. 
Table 7

Losses from Responding to Incorrect Concept for Potential Output

(Reported values are losses times $\left.10^{5}, \mathrm{TP} / \mathrm{DIS}\right)$

\begin{tabular}{|c|c|c|c|c|}
\hline \multirow{2}{*}{ Value of } & \multicolumn{4}{|c|}{ Value of $\omega$} \\
\cline { 2 - 5 }$\mu_{1}$ & 0.01 & 0.10 & 0.25 & 1.0 \\
\hline 0.5 & $4.37 / 6.67$ & $7.75 / 24.8$ & $22.7 / 39.7$ & $69.1 / 82.5$ \\
\hline 5.0 & $2.42 / 3.98$ & $4.93 / 22.7$ & $9.49 / 37.7$ & $39.8 / 81.4$ \\
\hline 50.0 & $1.63 / 3.38$ & $4.15 / 22.5$ & $9.05 / 37.7$ & $39.8 / 81.5$ \\
\hline 500.0 & $1.61 / 3.33$ & $4.17 / 22.5$ & $9.08 / 37.7$ & $39.8 / 81.5$ \\
\hline
\end{tabular}

${ }^{21}$ In these cases, the standard deviation of $u_{t}$ is, we think, fairly realistically calibrated. For the other tables, different values would have to be used. 
It is, of course, not clear that actual CBs behave as if $k$ exceeds zero, i.e., behave so as to aim for an output rate higher than the flexible-price (natural rate) value. The position that intelligent CBs do not aim for higher output values has been advanced by Svensson (1999), King (1996), and others. To us, nevertheless, it seems possible that positive values of $k$ might well reflect the behavior of some actual CBs, even ones with intelligent and inflation-adverse leaders, since $k>0$ would be a feature of CB preferences that accord with a welfare criterion based on individual utility functions in the presence of such real factors as monopolistic competition or tax distortions that imply that the flexible-price competitive equilibrium is not socially optimal (as shown by Woodford, 1999c). Of course, CBs may regard these real factors as more appropriately dealt with through devices other than monetary policy, and this, indeed, is the assumption about how real distortions are treated in many recent analyses of optimal monetary policy (including Woodford (1999c), Gali and Monacelli (1999), and Aoki (2000)). In any event, knowledge of the relative importance of this bias is relevant for the strategic decisions of CBs.

\section{Concluding Remarks}

Let us conclude with a very brief summary. We began by reviewing the distinction between the timeless perspective and discretionary modes of monetary policymaking, the former representing rule-based policy as formalized by Woodford (1999b). In the context of models with forward-looking expectations, this distinction is greater than in the models that have been typical in the rules-vs.-discretion literature. Typically, that is, there is a second inefficiency from discretionary policymaking, distinct from the more familiar inflationary bias. We have made calculations of the quantitative 


\section{Table 8}

DIS Losses Due to Inflation Bias

\section{Basic Model}

(Reported values are losses times $10^{5}$ )

\begin{tabular}{|c|c|c|c|c|}
\hline & & Value of $\omega$ & & \\
Value of $\alpha$ & 0.01 & 0.1 & 0.25 & 1.0 \\
\hline 0.10 & 0.1 & 10 & 62.5 & 1000 \\
\hline 0.05 & 0.4 & 40 & 250 & 4,000 \\
\hline 0.01 & 10 & 1000 & 6250 & 100,000 \\
\hline
\end{tabular}


magnitude of this second inefficiency or loss, using calibrated models of two types prominent in the current literature and a wide range of values representing the relative seriousness of inflation and output-gap variability. The magnitude of the losses is significant, but smaller in most cases than the inflationary bias from a one percent excess of the central bank's output target over the natural rate value. The losses tend to be somewhat larger in model specifications that imply inflation rate persistence and are often (but not universally) larger with more objective-function weight on output-gap variability.

In addition, we have examined the distinction between instrument rules and targeting rules; our results indicate that targeting-rule outcomes can be closely approximated by instrument rules that respond to any failure of the targeting rule's optimality condition to hold. Using the instrument rule formulation, a brief investigation of operationality issues, involving the unobservability of current output and perhaps inflation, is reported. In addition, a set of cases involving the assumption that the wrong concept of the natural-rate or potential level of output, essential in measuring the output gap, is used by the monetary policymaker. In all of the various cases examined in the paper, the performance of timeless perspective policymaking is at least as good as that provided by optimal discretionary behavior. Furthermore, these optimal rules can be well approximated by simple feedback rules with strong response parameters. 


\section{References}

Aoki, Kosuke (2000). “Optimal Commitment Policy Under Noisy Information.” Working Paper, Kobe University.

Archer, David J. (2000). "Inflation Targeting in New Zealand.” Paper presented at IMF Institute seminar on inflation targeting, March 20-21, 2000.

Barro, Robert J., and David B. Gordon (1983). "A Positive Theory of Monetary Policy in a Natural-Rate Model," Journal of Political Economy 91, 589-610.

Batini, Nicoletta, and Edward Nelson (2000). "Optimal Horizons for Inflation Targeting." Working paper No. 119, Bank of England.

Clarida, Richard, Jordi Gali, and Mark Gertler (1999). "The Science of Monetary Policy: A New Keynesian Perspective,” Journal of Economic Literature 37, 1661-1707.

Currie, David, and Paul Levine (1993). Rules, Reputation, and Macroeconomic Policy Coordination. Cambridge: Cambridge University Press.

Erceg, Christopher J., Dale W. Henderson, and Andrew T. Levin (1999). “Optimal Monetary Policy with Staggered Wage and Price Contracts." International Finance Discussion Paper 1999-640, Federal Reserve Board.

Freedman, Charles (2000). "The Canadian Experience with Targets for Reducing and Controlling Inflation." Paper presented at IMF Institute seminar on inflation targeting, March 20-21, 2000.

Gali, Jordi, and Mark Gertler (1999). "Inflation Dynamics: A Structural Econometric Investigation", Journal of Monetary Economics 44, 195-222.

Gali, Jordi, and Tommaso Monacelli (1999). “Optimal Monetary Policy and Exchange 
Rate Volatility in a Small Open Economy.” Working paper, Boston College.

Hamilton, James D. (1994). Time Series Analysis. Princeton University Press.

Jensen, Henrik (1999). “Targeting Nominal Income Growth or Inflation?”. Working paper, University of Copenhagen.

King, Mervyn A. (1996). "How Should Central Banks Reduce Inflation?_Conceptual Issues.” In Achieving Price Stability. Federal Reserve Bank of Kansas City.

King, Mervyn A. (1999). “The Monetary Policy Committee Two Years On,” Bank of England Quarterly Bulletin 39, 297-303.

King, Robert G., and Alexander L. Wolman (1999). "What Should the Monetary Authority Do When Prices are Sticky?” In John B. Taylor (ed.), Monetary Policy Rules. Chicago: University of Chicago Press. 349-398.

Klein, Paul (2000). "Using the Generalized Schur Form to Solve a Multivariate Linear Rational Expectations Model," Journal of Economic Dynamics and Control 24, 14051423.

Kydland, Finn E., and Edward C. Prescott (1977). "Rules Rather than Discretion: The Inconsistency of Optimal Plans," Journal of Political Economy 85, 473-493.

Kydland, Finn E., and Edward C. Prescott (1980). "Dynamic Optimal Taxation, Rational Expectations, and Optimal Control," Journal of Economic Dynamics and Control 2, 79 91.

Lucas, Robert E., Jr. (1980). "Rules, Discretion, and the Role of the Economic Advisor." In Stanley Fischer (ed.), Rational Expectations and Economic Policy. Chicago: University of Chicago Press. 
Lucas, Robert E., Jr., and Thomas J. Sargent (eds.) (1981). Rational Expectations and Econometric Practice. Minneapolis: University of Minnesota Press.

McCallum, Bennett T. (1999a). "Issues in the Design of Monetary Policy Rules." In John B. Taylor and Michael Woodford (eds.), Handbook of Macroeeconomics. Amsterdam: North Holland.

McCallum, Bennett T. (1999b). "Role of the Minimal State Variable Criterion in Rational Expectations Models.” In P. Isard, A. Razin, andd A. K. Rose (eds.), International Finance and Financial Crises: Essays in Honor of Robert P. Flood, Jr. Norwell, MA: Kluwer Academic Publishers. Also in International Tax and Public Finance 6 (November, 1999), 621-639.

McCallum, Bennett T., and Edward Nelson (1999a). "An Optimizing IS-LM Specification for Monetary Policy and Business Cycle Analysis," Journal of Money, Credit, and Banking 31, 296-316.

McCallum, Bennett T., and Edward Nelson (1999b). "Performance of Operational Policy Rules in an Estimated Semi-Classical Structural Model.” In John B. Taylor (ed.), Monetary Policy Rules, Chicago: University of Chicago Press. 15-45.

Orphanides, Athanasios (1999). “The Quest for Prosperity Without Inflation.” Working Paper, Federal Reserve Board.

Rotemberg, Julio J., and Michael Woodford (1999). "Interest Rate Rules in an Estimated Sticky Price Model.” In John B. Taylor (ed.), Monetary Policy Rules. Chicago: University of Chicago Press, 57-119.

Rudebusch, Glenn D., and Lars E. O. Svensson (1999). "Policy Rules for Inflation Targeting.” In John B. Taylor (ed.), Monetary Policy Rules. Chicago: University of 
Chicago Press, 203-246.

Smets, Frank (2000). “What Horizon for Price Stability?”. Working paper, European Central Bank.

Steinsson, Jon (2000). "Optimal Monetary Policy in an Economy with Inflation Persistence". Working paper, Princeton University.

Svensson, Lars E.O. (1997). "Inflation Forecast Targeting: Implementing and Monitoring Inflation Targets." European Economic Review 41, 1111-1146.

Svensson, Lars E.O. (1999). "Inflation Targeting as a Monetary Policy Rule,” Journal of Monetary Economics 43, 607-654.

Svensson, Lars E.O., and Michael Woodford (1999). "Implementing Optimal Policy Through Inflation-Forecast Targeting." Working paper, Princeton University.

Taylor, John B. (1979). "Estimation and Control of a Macroeconomic Model with Rational Expectations," Econometrica 47, 1267-1286.

Taylor, John B. (1993). "Discretion Versus Policy Rules in Practice," CarnegieRochester Series on Public Policy 39, 195-214.

Woodford, Michael (1999a). “Optimal Monetary Policy Inertia.” NBER Working Paper 7261.

Woodford, Michael (1999b). "Commentary: How Should Monetary Policy Be Conducted in an Era of Price Stability?" In: New Challenges for Monetary Policy: A Symposium Sponsored by the Federal Reserve Bank of Kansas City. Federal Reserve Bank of Kansas City. 277-316. 
Woodford, Michael (1999c). "Inflation Stabilization and Welfare." Chapter 6 of Interest and Prices, manuscript.

Woodford, Michael (2000). "Pitfalls of Forward-Looking Monetary Policy," American Economic Review Papers and Proceedings 90, 100-104. 